\title{
Knowledge on Prevention and Management of Preeclampsia and Eclampsia among Nurses in Primary Health Settings: Baseline Findings from an Inter- ventional Study in Dodoma Region, Tanzania.
}

\author{
Joho A Angelina ${ }^{\star}$, Stephen M Kibusib, Ipyana Mwampagatwa ${ }^{c}$, Alex Ernestc \\ aDepartment of Nursing and Midwifery, College of Health Sciences, University of Dodoma, bDepartment of Public Health, College of Health Sciences, University \\ of Dodoma, 'Department of Clinical Medicine, College of Health Sciences, University of Dodoma \\ Correspondence to Joho AAngelina (johoangeljoho@yahoo.co.uk)
}

\begin{abstract}
Background: Preeclampsia and eclampsia are conditions which increase maternal and foetal morbidity and mortality worldwide. These conditions are ranked as the second leading cause of maternal deaths. Nurses have a critical role in preventing and managing preeclampsia. However, their knowledge has not been evaluated particularly among those working in primary health facilities, where opportunities for continue education is limited.

Objective: To assess knowledge on prevention and management of preeclampsia and eclampsia among nurses working in the primary health care settings.

Methods: Analysis of baseline data from an intervention study which test the effectiveness of simulation-based training on obstetric and neonatal emergencies among nurses in managing maternal and newborn emergencies in primary health care settings. A total of 39 primary health centres within 7 districts in Dodoma Region were selected to take part in the interventional study. Individual participants were nurses working in maternity units were involved. 172 nurses were selected using a simple random method. Nurses' knowledge on prevention and management of PEE and its predictors were assessed using a self-administered questionnaire. Descriptive statistics analysis was done to determine the distribution of the background characteristics of nurses and logistic regression analysis was performed to explore predictors of nurses' knowledge

Results: Overall knowledge on preeclampsia and eclampsia was 88 (51.2\%). Professional qualification was a predictor associated with a nurse's knowledge about preeclampsia and eclampsia. Registered nurses were more knowledgeable compared to enrolled nurses (AOR3.311; CI, 1.62 to 6.768; $P$ value $=.001$ ), years of working experience showed no association with knowledge on preeclampsia and eclampsia (AOR 0.98; CI: 0.39-2.47; P values $=0.970$ )

Conclusion: This study showed there is a critical knowledge deficiency in the prevention and management of preeclampsia and eclampsia among nurses working in maternal units of primary health care setting. Effective regular training on prevention and management of preeclampsia and eclampsia for frontline nurses is required in order to improve maternal and neonatal survival.
\end{abstract}

\section{INTRODUCTION}

Worldwide, maternal and neonatal deaths are still a chalW lenge and it is estimated to be 211 maternal mortality rates per 100,000 livebirths as of 2017 . This represents a decrease of $38 \%$ from $2000^{1}$. However, neonatal mortality was estimated to be 18per 1000 livebirth as of 2017. This represents a reduction of $30.6 \%$ from $2000 .{ }^{2}$ In Sub-Sahan Africa, maternal mortality rate was estimated to be 525 per 100,000 livebirth as of 2017 , a reduction of $38.7 \%$ from $2000^{1}$. Furthermore, the neonatal mortality is still high and estimated to be 27.2 per 1000 live birth as of 2017, this is a reduction of $40.7 \%$ from $2000 .^{2}$ In Tanzania, there is no significant change in maternal and neo natal deaths, it is estimated that maternal mortality rate (MMR), has reduced from 854 as of 2000 to 524 deaths per 100,000 livebirths in $2017^{1}$. While neonatal mortality rate (NMR) was 26 in 2010, it was 25 deaths per 1,000 livebirths as of $2015^{3}$. Hypertensive disorders in pregnancy are responsible for about $26 \%$ of maternal deaths worldwide, in Africa the disorders cause deaths for about $99 \%{ }^{4}$. The vast majority of maternal deaths occur in low income countries. The Tanzania Demographic and Health Survey (TDHS) 2015-16 reported that sixteen percent of maternal deaths were due to hypertensive disorders, including eclampsia ${ }^{5}$. Furthermore, PEE are the main cause of maternal, foetal and neonatal mortality especially in low resource countries ${ }^{5}$. Preeclampsia and eclampsia (PEE) are serious conditions which increase long term disability, maternal and foetal, morbidity and mortality worldwide. ${ }^{6,7}$ Common hypertensive conditions during pregnancy include: new onset of high blood pressure during pregnancy (gestational hypertension), chronic hypertension, preeclampsia and eclampsia. Signs and symptoms of preeclampsia include: systolic blood pressure $>140 \mathrm{mmHg}$, diastolic blood pressure above $90 \mathrm{mmHg}$, proteinuria (above $0.3 \mathrm{~g} / 24 \mathrm{~h}$ ), frontal headache, visual disturbance and epigastric pain and substantial maternal organ dysfunction ${ }^{8}$. Complications of eclampsia include cardiovascular disease, renal disease, cerebrovascular disease and shorten life expectan$\mathrm{cy}^{9}$. Additionally, adverse foetal effects from PEE include intrauterine growth restriction, small for gestational age, respiratory 
distress syndrome, transient tachypnea of the newborn, anaemia, apnea, asphyxia, perior intraventricular haemorrhage, cardiomyopathy, cerebral palsy ${ }^{10,11}$ and persistent pulmonary hypertension of the newborn ${ }^{12}$. Furthermore, preeclampsia and eclampsia are leading causes of perinatal mortality ${ }^{11}$.

There are complex factors that impact timely care of women with PEE. Lack of competent frontline (nurses) health care providers' diagnosis and management especially in the area of maternal and neonatal emergency care may account for these deaths ${ }^{13}$. This account for third delay model for appropriate and timely management. However, if the woman comes to the antenatal clinic (ANC) or labour ward early to receive appropriate care while the nurse receiving the woman does not know how to diagnose and manage the PEE, this would put the woman and her unborn baby at increased risk of severe morbidity and or deaths.

Early detection, rapid response, accurate management and timely delivery of women with preeclampsia with severe features and eclampsia reduces maternal and foetal complications and deaths. Nurses' knowledge and skills about diagnosis and management of these conditions is critical factor in maternal and neonatal morbidity and mortality.

In Tanzania, the primary health centres are the entry point for most patients including pregnant women who seek health care services whenever needed. The primary health care centres are run by the clinical officers and few by the medical officers. Furthermore, majority of nurses who are working in the health centres are those with certificate and few with diploma in nursing. Moreover, the nursing training for those with diploma covers maternal and neonatal emergencies including PEE while those with certificate are not trained in maternal and neonatal emergencies $^{14}$. Nurses with certificate level of training are able to conduct normal delivery only, and equipped with skills to assist their senior nurses with diploma or health care providers (clinical and medical officers) in emergency or complicated labour. However, in real situation these nurses in some of health care centres are working independently without guidance from higher level nurses, clinical or medical officers.

In the rural areas most of the health centres are public ones, while in urban there are public and private health centres. In Dodoma, the health centres have the capacity of serving an average of 10,772 population, and the number of nurses per health centre ranges from 3 to 20 .

The referral health system in Tanzania is of a pyramidal pattern operating upwards from the lowest level which is the community. Patients are referred from community to dispensary, then to health centres, to district, to regional referral hospital, to consultant hospitals and national and or specialized hospitals. The referral system of patients from one level to another follows the skills which are required to address the problems of the patients. Moreover, the government has established an open-door policy, and hence patients can be referred from lower level to higher if the other referral levels lack the required skills ${ }^{15}$.

Nurses are crucial frontline healthcare providers in Tanzania's healthcare facilities. Their knowledge and skills in managing obstetric emergencies are of paramount importance. They must be able to provide timely lifesaving emergency care and correctly identify women needing referral to a higher level of care ${ }^{16}$. Healthcare training programs for nurses on the prevention and management of eclampsia have been shown to reduce adverse outcomes in critical patientcare settings ${ }^{17}$. Moreover, strengthening on the job training regarding emergency care helps to improve nurses' level of knowledge of PEE management ${ }^{18}$.

Essential knowledge for handling maternal emergencies, including eclampsia, is a prerequisite to appropriate treatment and referrals for mothers. Lack of core knowledge leads to poor decision making and management of emergency maternal health conditions. Furthermore, insufficient knowledge can be attributed to delays in treatment and referrals ${ }^{19,20}$. Adequate knowledge is required to correctly identify women with preeclampsia with and without severe features. This foundational knowledge helps ensure timely evidence based decision making and care based on international guidelines. In Central Tanzania, the knowledge of nurses about the management of PEE, is not well known. Therefore, the aim of this study was to assess nurses' knowledge on managing PEE and identify the predictors of nurses' knowledge in the primary health care setting in Dodoma Region.

\section{METHODS}

\section{Study Design and Target Population}

This paper present analysis of baseline data from an intervention study which aim at testing the effectiveness of simulation-based training on obstetric and neonatal emergencies among nurses in managing maternal and newborn emergencies in primary health care settings. The study was conducted between May and June 2017, exploring nurses' knowledge on PEE. Study participants were nurses working in antenatal ward, labour, postnatal and theatre units.

\section{Study Setting}

This study was conducted in all seven districts in Dodoma Region namely Mpwapwa, Kogwa, Chamwino, Dodoma Municipal, Bahi, Chemba and Kondoa. A total of 39 health centres in the region ( 27 government, 4 faith based organization, 3 parastatal and 5 private). All health centres included in the study are providing ANC services free of charge. On average, a health centre serves 10,772 population, and staffed with 3 to 20 number of nurses. Dodoma Region was selected for this study because of high maternal deaths of 512 per 100,000 livebirths compared to the surrounding regions Singida (468), Manyara (376) and Iringa (292) per 100,000²1.

\section{Sampling Technique and Sample Size}

The districts were selected purposively due to high maternal deaths in Dodoma Region and all 39 health centers in Dodoma were included in the study. Simple random method was used to select participants from maternity units (antenatal, labour ward, and postnatal) and theatre unit. A 50\% rule based on researcher's convenience was considered as a criterion for a decision for the number of nurses to recruit from health centres. Therefore, for each health centre half of its nurses were included in the study. This is due to shortage of nurses, in the health centres, nurses are working in multiple sections, and they don't have specific work. A self-administered questionnaire was used to assess nurses' knowledge on the prevention and management of PEE. A total of 176 study participants were recruited based on a sample size calculation using the Kish and Leslie formula ${ }^{22}$ $\left(\mathrm{n}=\underline{\mathrm{Z}^{2}} \mathrm{p}(1-\mathrm{p}) / \mathbf{e}^{2}\right)$ whereby $\mathrm{n}$ is a minimum sample size, $\mathrm{z}$ is a constant, standard normal variation (1.96 for $95 \%$ confidence level) $\mathrm{p}=11.8 \%$ a prevalence reported by the study conducted in Moshi municipality in northern Tanzania on the evaluation of knowledge and management practices of hyper tension in preg- 
nancy ${ }^{23}$. Considering a margin of error (e) of 5\%. The minimum required sample size was 160 and we added $10 \%$ for non-response. The total sample size was 176 nurses and response rate was $97.7 \%$.

\section{FIGURE 1: Distribution of number of deliveries per District in Dodoma Region for the year 2017}

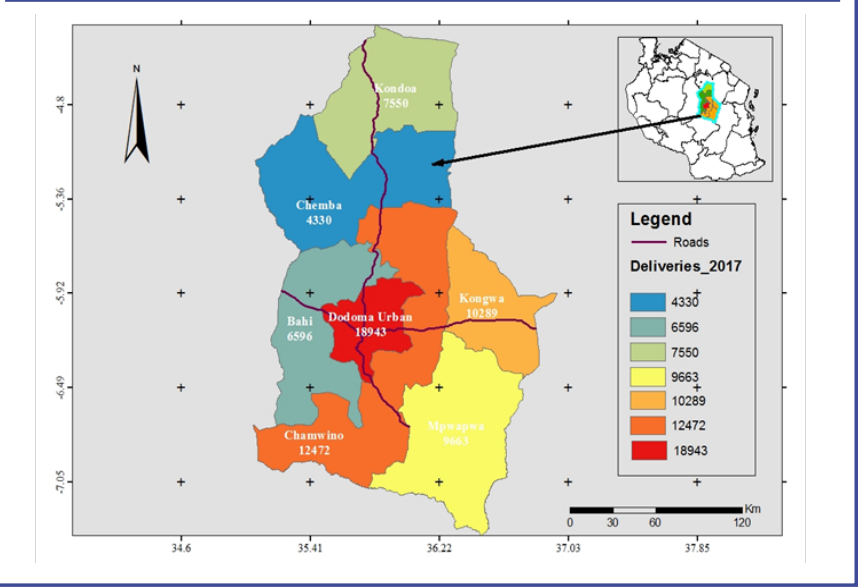

\section{Data Collection Tool}

In this study, data was collected using a standardized questionnaire in Kiswahili, the national language of Tanzania. Knowledge about PEE was assessed using a standardised and validated questionnaire which contained 10 items with a total of 20 correct answers. The tool was adapted from Jhpiego education materials $^{24,25}$. The questionnaire contained three sections. The first section reviewed the nurses' demographic characteristics, the second section explored their educational background and the third section assessed nurses' knowledge about the management of obstetric emergency including PEE. Each item with a correct response received one point and incorrect responses were scored as zero. Respondents who scored 15 marks and above (75\% and beyond) were categorized into adequate knowledge group. Those who scored below 15 marks were categorized into inadequate knowledge group. Before the actual data collection process, a pilot study was conducted with 20 nurses working at district hospital to test the tool's ability to obtain needed information prior to data collection and to identify confusing or ambiguous questions. Ambiguous questions were reworked or removed. Nurses included in the pilot study were not included in the final study.

\section{Data Collection Procedure}

The study was conducted in the antenatal ward, labour ward, postnatal ward and theatre units where nurses provide care to mothers with PEE. Participation in the study was voluntary. Self-administered questionnaire was completed by each nurse in the presence of researcher and assistant. Clarification was provided in case participants were not clear or had questions about the tool.

\section{Dependent and Independent Variables}

The dependent variable was the knowledge of nurses on management of PEE. Independent variables included age, sex, experience working in the maternal unit, professional qualification, duration of professional training and timing of work shift.

\section{Data Analysis}

Data entry and statistical analysis were performed using IBM SPSS Statistics for Windows version 20.0 (IBM Corp, Armonk, NY, USA $)^{26}$. Descriptive analysis was performed to explore distribution of demographic characteristics of respondents. Knowledge items were computed to obtain total knowledge score which was categorized into adequate knowledge and inadequate knowledge. Thereafter, a cross tabulation analysis was performed to assess relationship between categorical variables. Chi-squaretest was used to determine significant relationship between categorical variables. Significant relationships were further analyzed by performing simple logistic regression analysis. All variables with significant relationship with knowledge $(P$ value $<.05)$ were included in the multiple logistic regression.

\section{Ethical Considerations}

Ethical clearance was obtained from the Institutional Research Review Committee of the University of Dodoma in Dodoma Region, Tanzania. Permission to conduct the study was obtained from the Regional Medical Officer and the District Medical Officers from respective districts within Dodoma Region. The aim of the study was clearly explained to the participants before signed the consent form. The participants were informed that participation in the study was completely voluntary and they can withdraw at any stage without incurring any consequences. There was no reasonable risk of harm to the participants. The anonymity of the participants was ensured by not having any identification on the data collection tool so that information would not be traced back to individuals. Confidentiality was guaranteed by storing data in a safe and locked place, and only the researcher had access to the raw data.

\section{RESULTS}

A total of 172 nurses from 39 health centres in Dodoma Region participated in the study. This corresponds to a $97.7 \%$ response rate. Mean age the nurses who responded to the questionnaire was 37.3 years $(\mathrm{SD} \pm 11.393)$ and majority were females 145 $(84.3 \%)$ and most 109 (63.4\%) being enrolled nurses (certificate level of training). Three quarter of them had completed educational training of less than three years with slightly above half of them working in maternity unit for less than 5 years and received training on management and prevention of PEE as part of their nursing education (See Table 1).

\section{Level of nurses' knowledge on management of pre-eclamp- sia and eclampsia}

Based on the operational definition used in this study, only 88 $(51.2 \%)$ were found to have adequate knowledge on the management of pre-eclampsia and eclampsia. Those who scored 75 percent and above on the self-administered questionnaire were categorised as having adequate knowledge (See Figure 2).

\section{Nurses' responses to question related to knowledge on prevention and management of eclampsia}

Nurses were given 10 multiple answer questions, with total of 20 correct answers. Most nurses 160 (93\%) were able to correctly identify the recommended drug to be used for prevention and management of severe preeclampsia and eclampsia and 148 $(86 \%)$ nurses were able to recognize the drug of choice for the management of high blood pressure. However, few nurses, 67 $(39 \%)$, were able to know the type of intravenous fluid to be given to mothers with eclampsia (See Table 2). 
TABLE 1: Nurses' Demographic Characteristics N=172

\begin{tabular}{|c|c|c|}
\hline Demographic characteristics & Frequency & $\begin{array}{c}\text { Percentage } \\
(\%)\end{array}$ \\
\hline $\begin{array}{l}\text { Male } \\
\text { Female }\end{array}$ & $\begin{array}{l}27 \\
145\end{array}$ & $\begin{array}{l}15.7 \\
84.3\end{array}$ \\
\hline $\begin{array}{l}\text { Age Group (Years) } \\
20-29 \\
30-39 \\
40 \text { and above }\end{array}$ & $\begin{array}{l}63 \\
39 \\
70\end{array}$ & $\begin{array}{l}36.6 \\
22.7 \\
40.7\end{array}$ \\
\hline $\begin{array}{l}\text { Level of professional } \\
\text { Enrolled nurses } \\
\text { Registered nurses }\end{array}$ & $\begin{array}{l}109 \\
63\end{array}$ & $\begin{array}{l}63.4 \\
36.6\end{array}$ \\
\hline $\begin{array}{l}\text { Years of professional training } \\
\text { Less than or equal to } 3 \\
\text { Above } 3\end{array}$ & $\begin{array}{l}120 \\
52\end{array}$ & $\begin{array}{l}69.8 \\
30.2\end{array}$ \\
\hline $\begin{array}{c}\text { Experience in the health sector } \\
\text { Less than } 5 \text { years } \\
5 \text { years and above }\end{array}$ & $\begin{array}{l}70 \\
102\end{array}$ & $\begin{array}{l}40.7 \\
59.3\end{array}$ \\
\hline $\begin{array}{c}\text { Experience in maternity (years) } \\
\text { Less than } 5 \text { years } \\
5 \text { years and above }\end{array}$ & $\begin{array}{l}95 \\
77\end{array}$ & $\begin{array}{l}55.2 \\
44.8\end{array}$ \\
\hline $\begin{array}{l}\text { Pre-service training on } \\
\text { eclampsia management } \\
\text { Yes } \\
\text { No }\end{array}$ & $\begin{array}{l}90 \\
82\end{array}$ & $\begin{array}{l}52.3 \\
47.7\end{array}$ \\
\hline $\begin{array}{l}\text { Night shifts } \\
\text { No } \\
\text { Yes }\end{array}$ & $\begin{array}{l}56 \\
116\end{array}$ & $\begin{array}{l}32.6 \\
67.4\end{array}$ \\
\hline $\begin{array}{c}\text { Number of shifts per day } \\
\text { Two } \\
\text { Three }\end{array}$ & $\begin{array}{l}27 \\
145\end{array}$ & $\begin{array}{l}15.7 \\
84.3\end{array}$ \\
\hline
\end{tabular}

Factors associated with nurses' level of knowledge on prevention and management of preeclampsia and eclampsia. In cross tabulation analysis, nurses' level of knowledge on prevention and management of PEE was significantly associated with age $(P<.001)$, professional qualification $(P$ value $=.002)$, duration of professional training $(P$ value $=.034)$, working experience in the health sector $(P<.001)$ and experience in maternity unit $(P<.001)$. High proportion of older $(70 \%)$, more qualified nurses $(66 \%)$ and those with longer years of professional training $(64 \%)$ and experience $(63 \%)$ had adequate knowledge on management of PEE (See Table 3).

In binary logistic regression, age, professional qualification, years of training and work experience maintained their significant association with nurses' level of knowledge on management of PEE. Registered nurses, those aged 40 years and above, and those with longer duration of professional training and working experience were more likely to have adequate knowledge on management of PEE (Table 4). However, in multiple logistic regression, only professional qualification maintained its significant association with knowledge on management of PEE. Registered nurses were three times more likely (AOR
$3.3 ; 95 \% \mathrm{CI}, 1.6$ to 6.8 ) to have adequate knowledge on management of PEE than enrolled nurses (See Table 4).

\section{FIGURE 2: Knowledge Level Regarding Pre-eclampsia and Eclampsia Management}

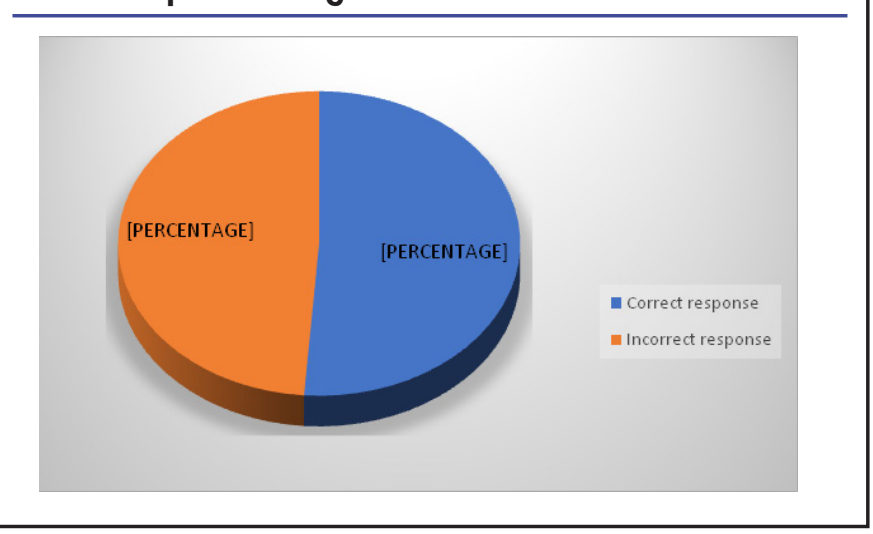

\section{DISCUSSION}

This study aimed to assess nurse's knowledge of PEE, their prevention and management and associated factors among nurses working in the primary health care setting in Dodoma Region, Tanzania. Out of 172 study participants, 88 (51.2\%) had adequate PPE management knowledge. Nurses' knowledge level on management of PEE in the current study was somehow comparable to a previous study conducted in public health facilities in Dar es Salaam, Tanzania which reported 76 (55\%) of nurses as knowledgeable ${ }^{27}$ Nurses in the current study were less knowledgeable compared with results of the study conducted in Egypt which reported that $30 \%$ of nurses had poor knowledge regarding eclamptic care ${ }^{28}$. However, another study conducted in Egypt reported that $17 \%$ of nurses had optimal knowledge on management of preeclampsia ${ }^{8}$. Differences between these studies may be explained by approaches to pre-service and in-service training, lack of empowerment and also, lack of supportive supervision. Regardless, findings from all of these studies demonstrate that knowledge on PEE management is low among frontline nurses in these low resource settings.

Although majority of nurses (93.6\%) knew that magnesium sulphate (MgSO4) is the drug of choice for the management of woman with eclampsia or preeclampsia with severe, few nurses $(38.4 \%)$ knew its maintenance dose and how to correctly assess for toxicity after administration of $\mathrm{MgSO} 4$. Our study results are similar to other studies whereby nurses were also able to correctly identify $\mathrm{MgSO} 4$ as the medication of choice. However, the specifics of MgSO4 dosing, administration and monitoring is of grave concern ${ }^{29}$. The low knowledge observed in the current study for the management of PEE, may reflect low knowledge in other areas of maternal health care, including antenatal, intrapartum and postpatum care, which ultimately affects maternal and neonatal outcomes. Appropriate and timely care at the health facilitity is crucial to improve outcomes and avoid delays in care. Better understanding the factors that contribute to such delays will help the health system improve care quality and outcomes ${ }^{20}$. The current study revealed majority had been working as nurses in maternity for less than five years. This means nurses with good working experience in maternal a- 
TABLE 2: Number and Percentage of Nurses with Correct Responses to Prevention and Management of Preeclampsia and Eclampsia

Questions
What are the immediate managements during fit?
Shout for help

Frequency (\%)

Shout for help

Ensure the woman airway is open

$112(65.1)$

$143(83.1)$

What care should be provided for a women after convulsion?

If available give oxygen 4-6 liters per minutes by mask or canula.

Observe color for cyanosis and need for oxygen.

Aspirate the mouth and throat as necessary

$124(72.1)$

$82(47.7)$

$155(90.0)$

What kind of assessment/physical examination needed after convulsions/fits

Observe color for cyanosis and need for oxygen, Check for aspiration: lungs should always ascultated after

the convulsion has ended, Check vital signs and fetal heart rate.

The recommended intravenous line for managing eclampsia is

Normal saline (NS) or Ringer's lactate

The recommended drug used to control convulsion in management of eclampsia is Magnesium sulfate

160(93.0)

The recommended dose of that drug (selected in question 5) during control of convulsion is

Gives Magnesium sulfate 20\% solution, 4g IV slowly over 5-10 minutes OR $10 \mathrm{~g}$ of Magnesium sulphate,

each buttock $5 \mathrm{~g}$ with $50 \%$ solution deep IM injection with $1 \mathrm{ml}$ of $2 \%$ lignocaine in the same syringe.

What is the prevention of toxicity of drug selected in question 5 ?

Assess respiratory rate. Is respiratory rate at least 16 per minute?

Assess patellar reflexes. Is Patellar reflexes present?

Assess urinary output. Is Urinary output at least $30 \mathrm{~mL}$ per hour over preceding four hours?

131(76.2)

$113(65.7)$

$133(77.3)$

What are the immediate measures in case the toxicity of the drug selected in question $\mathbf{5}$ happens?

Withhold or delay the drug if respiratory rate falls below 16 per minute

Withhold or delay the drug if Patellar reflexes are absent and Urinary output falls below $30 \mathrm{ml}$ per hour over

the preceding 4 hours.

Assess ventilation and give Calcium Gluconate $1 \mathrm{gm}$ (10 $\mathrm{ml}$ in 10\% solution).

$86(50.0)$

94(54.7)

$127(73.8)$

If diastolic blood pressure remains above $110 \mathrm{mmhg}$, the recommended group of drugs used is

Antihypertensive drugs (nifedipine or hydralazine)

$148(86.0)$

Others management of eclampsia includes

Insert an indwelling urinary catheter to monitor urinary output and proteinuria, do a bed side clotting test,

never leave the woman alone (convulsion followed by aspiration of vomit may cause death to a woman and fetus)

Record drug administration and findings on the woman 's record, Share your findings to a woman and as appropriate to her partner or family member

Explain management, based on diagnosis, and the importance for pregnancy, labor and delivery.

93(54.1)

91(52.9)

60(34.9)

This Table describe the steps of management of pre-eclampsia and eclampsia; showing nurses response to the given questions

nd neonatal emergencies management are not retained in the labour ward. Our results differed with study conducted in Northern Nigeria whereby most of health providers had mean number of 9.6 year experience in managing PEE, and most of them knew MgSO4 is the drug of choice in preventing and treating PEE. ${ }^{30}$ The experienced nurses in labour ward should be considered as a good resource for teaching newly employed nurses on management of eclampsia and other maternal and neonatal emergencies.

The current study revealed educational preparation as a key predictor of an individual nurse's knowledge of management of preeclampsia and eclampsia. After controlling for possible confounders, registered nurses were three more likely to be knowledgeable about PEE management compared to enrolled nurses. In Tanzania, registered nurses complete educational training programs for 3 years (2008-present) or 4 years (prior to 2008) compared to enrolled nurses who receive 3 years (prior 2008) or 2 years (2008-present) of educational preparation. A difference in knowledge and also skills among differently trained nurses has been demonstrated in other settings in Sub-Saharan Afri$\mathrm{ca}^{31}$. Policymakers and educators need to consider the effectiveness of 2 year certificate nurse training programs compared with registered nursing training programs. It appears that there are major knowledge gaps despite comprehensive curricula. Innovative approaches are needed in all types of nurse training programs in Tanzania to ensure foundational knowledge and skills in obstetric and neonatal emergencies, including severe preeclampsia and eclampsia. To ensure that every birth attendant is truly skilled ${ }^{32}$, frontline nurses require core knowledge and fluency in lifesaving skills for mothers and neonates. To th- 
TABLE 3: Factors Associated With Nurses' Level of Knowledge on Prevention and Management of Preeclampsia and Eclampsia ( $\mathrm{N}=172)$

\begin{tabular}{|c|c|c|c|c|}
\hline Demographic characteristics & \multicolumn{2}{|c|}{ Knowledge on PEE management } & \multirow{2}{*}{$\frac{x^{2}}{2.558 \mathrm{a}}$} & \multirow{2}{*}{$\frac{\text { P-value }}{0.110}$} \\
\hline $\begin{array}{ll}\text { Sex } & \text { Male } \\
& \text { Female }\end{array}$ & $\begin{array}{l}17(63.0) \\
67(46.2)\end{array}$ & $\begin{array}{l}10(37.0) \\
78(53.8)\end{array}$ & & \\
\hline $\begin{array}{l}\text { Age (years) } \\
\begin{array}{l}20-29 \\
30-39 \\
40 \text { and above }\end{array}\end{array}$ & $\begin{array}{l}42(66.7) \\
21(53.8) \\
21(30.0)\end{array}$ & $\begin{array}{l}21(33.3) \\
18(46.2) \\
49(70.0)\end{array}$ & $18.348 \mathrm{a}$ & 0.001 \\
\hline $\begin{array}{l}\text { Level of professional } \\
\text { Enrolled nurses } \\
\text { Registered nurses }\end{array}$ & $\begin{array}{l}63(57.8) \\
21(33.3)\end{array}$ & $\begin{array}{l}46(42.2) \\
42(66.7)\end{array}$ & $9.564 \mathrm{a}$ & 0.002 \\
\hline $\begin{array}{l}\text { Duration of professional training } \\
\text { Less than or equal to } 3 \\
\text { Above } 3\end{array}$ & $\begin{array}{l}65(54.2) \\
19(36.5)\end{array}$ & $\begin{array}{l}55(45.8) \\
33(63.5)\end{array}$ & $4.512 \mathrm{a}$ & 0.034 \\
\hline $\begin{array}{c}\text { Experience in the health sector } \\
\text { Less than } 5 \text { years } \\
5 \text { years and above }\end{array}$ & $\begin{array}{l}46(65.7) \\
38(37.3)\end{array}$ & $\begin{array}{l}24(34.3) \\
64(62.7)\end{array}$ & $13.456 \mathrm{a}$ & 0.001 \\
\hline $\begin{array}{c}\text { Experience in maternity unity } \\
\text { Less than } 5 \text { years } \\
5 \text { years and above }\end{array}$ & $\begin{array}{l}57(60.0) \\
27(35.1)\end{array}$ & $\begin{array}{l}38(40.0) \\
50(64.9)\end{array}$ & $10.583 \mathrm{a}$ & 0.001 \\
\hline $\begin{array}{c}\text { Number of shifts per day } \\
\text { Two shifts } \\
\text { Three shifts }\end{array}$ & $\begin{array}{l}10(37.0) \\
74(51.0)\end{array}$ & $\begin{array}{l}17(63.0) \\
71(49.0)\end{array}$ & $1.785 \mathrm{a}$ & 0.182 \\
\hline $\begin{array}{l}\text { Working night shift } \\
\text { No } \\
\text { Yes }\end{array}$ & $\begin{array}{l}28(50.0) \\
56(48.3)\end{array}$ & $\begin{array}{l}28(50.0) \\
60(51.7)\end{array}$ & $.045 \mathrm{a}$ & 0.832 \\
\hline $\begin{array}{l}\text { Pre-service training on eclampsia } \\
\text { Yes } \\
\text { No }\end{array}$ & $\begin{array}{l}49(54.4) \\
35(42.7)\end{array}$ & $\begin{array}{l}41(45.6) \\
47(57.3)\end{array}$ & $2.375 \mathrm{a}$ & 0.123 \\
\hline
\end{tabular}

at end, there is a need to examine the duration of study for licensure and effectiveness of pre-service training for nurses in Tanzania.

\section{CONCLUSION}

This study demonstrated a critical gap in knowledge among frontline nurses providing maternal health care in Dodoma, Tanzania. One wonders about other key knowledge gaps among maternal health nurses in this setting. At a minimum, nurses are in dire need of regular refresher trainings that focus on lifesaving knowledge and skills for obstetrics, including the management of pre-eclampsia and eclampsia. Strengthening on job training will help nurses' readiness for obstetric emergencies, including early detection, proper management and timely referral. By improving the knowledge and skills of frontline nurses, we can improve maternal and neonatal outcomes. We also, recommend continuing medical educations (CMEs) within the department and supportive supervision to empower nurse's knowledge on obstetric emergencies.
Limitation of the study: The study was conducted in all districts of Dodoma region only, therefore these results cannot be generalized to all nurses in Tanzania. The data collection was done for the period of one month (May to June 2017), to obtain for representative data we would have longer time.

\section{Abbreviations}

TDHS: Tanzanian Demographic and Health Survey

PEE: Pre-eclampsia and eclampsia

MgSO4: Magnesium Sulphate

WHO: World Health Organization.

Jhpiego: Johns Hopkins Program for International Education in Gynaecology and Obstetrics.

Funding: The authors have indicated that they have no financial relationship relevant to this manuscript disclose. 
TABLE 4: Predictors of Nurses' Knowledge on Prevention and Management of Preeclampsia and Eclampsia ( $N=172)$

\begin{tabular}{|c|c|c|c|c|c|c|}
\hline Demographic characteristics & & 95\% C.I. & & & 95\% C.I. & \\
\hline & OR & Lower Upper & p value & AOR & Lower Upper & p value \\
\hline
\end{tabular}

\section{Sex}

Male

Female

Age (years)

20-29

30-39

40 and above

\section{Professional qualification}

Enrolled

Registered

Duration of professional training

$<3$ years

$\geq 3$ years

\section{Experience in $\mathrm{H} / \mathrm{S}$}

$<5$ years

$\geq 5$ years

\section{1}

0.85

1

$\begin{array}{llll}1.71 & 0.76 & 3.89 & 0.197\end{array}$

4.67

2.25

9.70

0.000

1

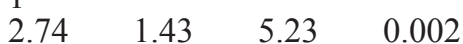

0.002

\section{1} 2.05$$
5.23
$$

$\begin{array}{lll}1.05 & 4.01 \quad 0.035\end{array}$

1

$\begin{array}{lll}1.71 & 6.10 \quad 0.000\end{array}$

.035

Experience in the maternity unit

$<5$ years

$\geq 5$ years 1 $\begin{array}{llll}2.78 & 1.49 & 5.18 & 0.001\end{array}$

0.98

0.39

2.47

0.970

1.20

4.19

0.34

0.97

4.28

0.776

$18.22 \quad 0.056$

3

1.62

6.77

0.001

1.35

0.35

5.25

0.661

0.96

0.31

2.96

0.937
Authors' contributions: Angelina Joho led the conceptual, design, acquisition of data, analysis, interpretation of data, and drafting of the manuscript. Stephen Kibusi, Alex Ernes and Ipyana Mwampagatwa guided the conception, design and acquisition of the data, analysis and interpretation, and critically revised the manuscript for intellectual content. All authors read and approved the final manuscript.

Data Availability: Data set is available upon request to the corresponding author.

Acknowledgements: The authors wish to thank the University of Dodoma for their support of this study and all research assistants and nurses who participated in the study. Also, we wish to thank Elisa Vandervort for her expertise in editing this manuscript.

\section{REFERENCES}

1. World Health Organization. Trends in Maternal Mortality 2000 to 2017: Estimates by WHO, UNICEF; 2019.

2. Hug L, Alexander M, You D, Alkema L. National, regional, and global levels and trends in neonatal mortality between 1990 and 2017, with scenariobased projections to 2030: a systematic analysis. Lancet Glob Heal. 2019;7(6):e710-e720. doi:10.1016/S2214109X(19)30163-9

3. TDHS. Tanzania:2015-16 Demographic and Health Survey andMalaria Indicator Survey Key Findings; 2015.

4. WHO. Trends in Maternal Mortality: 1990 to 2015 Estimates by WHO, UNICEF, UNFPA, World Bank Group and the United
Nations Populations Division; 2015.

5. Mol BWJ, Roberts CT, Thangaratinam S, Magee LA, De Groot CJM, Hofmeyr GJ. Pre-eclampsia. Lancet. 2016;387(10022):9991011. doi:10.1016/S0140-6736(15)00070-7

6. WHO. Policy of Interventionist versus Expectant Management of Severe Pre-Eclampsia before Term; 2018.

7. Say L, Chou D, Gemmill A, et al. Global causes of maternal death: A WHO systematic analysis. Lancet Glob Heal. 2014;2(6). doi:10.1016/S2214-109X(14)70227-X

8. Safaa S. Ahmed; Hanaa K. Helmy; Amel A. Mohamed. Impact of a tailored intensive educational program upon preeclampsia on nurses'knowledge at Beni-Suef City, Egypt. Int J Nurs Sci. 2017;7(4):79-83.

9. Beena Varghese, Jayanna Krishnamurthy, Blaze Correia, Ruchika Panigrahi, MaryannWashington, Vinotha Ponnuswamy PM. Limited effectiveness of a skills and drills intervention to improve emergency obstetric and Newborn Care in Karnataka, India: A Proof-of-Concept Study. ghsp. 2016;4(4).

10. American Academy of Pediatrics. Helping Baby Breathe. Second edition Pediatrics. 2009.

11. Ahmed Y. Perinatal. Perinatal Mortality and associated factor in Jimma University Specialized. 2017;(June). doi:10.4172/21610932.1000409

12. Walker D, Cohen S, Fritz J, et al. Team training in obstetric and neonatal emergencies using highly realistic simulation in Mexico: impact on process indicators. BMC Pregnancy Childbirth. 2014;14(1):1.

13. BuchmannE J, StonesW, Thomas N. Preventing deaths from complications of labour and delivery. Best Pract Res Clin Obstet Gynaeco 
l. 2016 Oct;36:103-115. doi: 10.1016/j.bpobgyn.2016.05.012. Epub 2016 Jun 26.

14. Ministry of Health, Community Development, Gender, Elederly and Children.Curriculum_NTA_Level_4_27 in Nursing and Midwifery. 2017.

15. Kwesigabo G, Mwangu MA, Kakoko DC, et al. Tanzania's health system and workforce crisis Published by : Palgrave Macmillan Journals Stable URL : http://www.jstor.org/stable/23319321 Linked references are available on JSTOR for this article: Tanzania's health system and workforce crisis. J Public Heal Policy This. 2017;33:35-44.

16. Shraddha Verma, Manisha Jain CB. Obstetric emergencies: preparedness among nurses for safe motherhood. Int J Reprod Contraception, Obstet Gynecol. 2016;5(4):998-1001.

17. Daniels K, Arafeh J, Clark A, Waller S, Druzin M, Chueh J. Prospective randomized trial of simulation versus didactic teaching for obstetrical emergencies. Simul Healthc. 2010;5(1):40-45.

18. Kidanto HL, Mogren I, van Roosmalen J, et al. Introduction of a qualitative perinatal audit at Muhimbili National Hospital, Dar es Salaam, Tanzania. BMC Pregnancy Childbirth. 2009;9(1):1.

19. Otolorin E, Gomez P, Currie S, Thapa K, Dao B. Essential basic and emergency obstetric and newborn care: from education and training to service delivery and quality of care. Int J Gynecol Obstet. 2015;130(S2):S46-S53. doi:10.1016/j.ijgo.2015.03.007

20. Knight HE, Self A, Kennedy SH. Why are women dying when they reach hospital on time? A systematic review of the 'third delay.' PLoS One. 2013;8(5):e63846.

21. National bureau of statistics (NBS). Mortality and Health Monograhpy. Dar es Salaam; 2015. https://www.dhsprogram.com/pubs/ pdf/SR233/SR233.pdf.

22. Leslie K. Survey Sampling; 1965.

23. Elisabeth B, Lohre B, Liljevik S. Evaluation of knowledge and management practices of hypertension in pregnancy among health care workers in Moshi University of Oslo Norway. 2012:1-41.

24. Jhpiego. Helping Mothers Survive: Bleeding After Birth, Traing Package. Help Mothers Survive. 2014.

25. Jhpiego. Helping Mothers Survive Pre-Eclampsia \& Eclampsia Training Package.2018.

26. IBM. IBM SPSS Statistics for Windows, Version 20.0. Armonk, NY: IBM Corp. 20th ed. Chicago New york; 2011.

27. Luzango E. Maembe ABP. Managing pre-eclampsia and eclampsia in Dar es Salaam public health facilities: A focus on equipment, supplies, drugs and knowledge of healthcare workers. Tanzania Med J. 2015;27(1).

28. El Rheem Emam E, Mousa Saber N. Effect of Nursing Program on Improving Nurses' Knowledge and Skills Regarding Care of Eclamptic Women. Am J Nurs Res. 2018;6(7):430-436. doi:10.12691/ajnr-6-7-4

29. Murphy GAV, Gathara D, Mwaniki A, et al. Nursing knowledge of essential maternal and newborn care in a high-mortality urban African setting: A cross-sectional study. J Clin Nurs. 2018;(October 2018):882-893. doi:10.1111/jocn.14695

30. Oguntunde $\mathrm{O}$, Charyeva Z, Cannon M, et al. Factors influencing the use of magnesium sulphate in pre-eclampsia/eclampsia management in health facilities in Northern Nigeria: A mixed methods study. BMC Pregnancy Childbirth. 2015;15(1):1-8. doi:10.1186/s12884-015-0554-8

31. Ameh CA, Kerr R, Madaj B, et al. Knowledge and skills of healthcare providers in sub-Saharan Africa and Asia before and after competency-based training in emergency obstetric and early newborn care. 2016:1-14. doi:10.1371/journal.pone.0167270

32. WHO;ICM;FIGO. Making pregnancy safer: the critical role of the skilled attendant. A joint statement by WHO, ICM and FIGO. Geneva, Switz WHO. 2004:1-18. doi:http://whqlibdoc.who.int/ publications/2004/9241591692.pdf

33. Walker DM, Holme F, Zelek ST, et al. A process evaluation of PRONTO simulation training for obstetric and neonatal emergency response teams in Guatemala. BMC Med Educ. 2015;15(1). doi:10.1186/s12909-015-0401-7

34. Christmas A, Mahapatra T, Sterling M, et al. Simulation-enhanced nurse mentoring to improve preeclampsia and eclampsia care: an education intervention study in Bihar, India. BMC Pregnancy Childbirth. 2019;19(1):1-9. doi:10.1186/s12884-019-2186-x

35. Ricca J. Limits of "skills and drills" interventions to improving obstetric and newborn emergency response: what more do we need to learn? Glob Heal Sci Pract. 2016;4(4):518-521. doi:10.9745/GHSP-D-16-00372

\section{Peer Reviewed}

Funding: University of Dodoma

\section{Competing Interests: None}

Received: $3^{\text {rd }}$ May $2019 \quad$ Accepted: $20^{\text {th }}$ May 2020

Cite this article as: Joho AA, Kibusi MS, Mwampagatwa I, Ernest A. Knowledge on Prevention and Management of Preeclampsia and Eclampsia among Nurses in Primary Health Settings: Baseline Findings from an Interventional Study in Dodoma Region, Tanzania. East Afr Health Res J. 2020;4(1):33-40. https://doi.org/10.24248/eahrj. $\underline{\mathrm{v} 4 \mathrm{i} 1.619}$

C Joho et al. This is an open-access article distributed under the terms of the Creative Commons Attribution License, which permits unrestricted use, distribution, and reproduction in any medium, provided the original author and source are properly cited. To view a copy of the license, visit http://creativecommons.org/licenses/by/4.0/. When linking to this article, please use the following permanent link: https://doi.org/10.24248/eahrj.v4i1.619 